\title{
Muscle cell components dictate hepatocyte gene expression and the distribution of the Golgi apparatus in heterokaryons
}

\author{
Steven C. Miller, ${ }^{1,2}$ Grace K. Pavlath, ${ }^{1,3}$ Bruce T. Blakely, ${ }^{1}$ and Helen M. Blau ${ }^{1}$ \\ ${ }^{1}$ Department of Pharmacology, Stanford University School of Medicine, Stanford, California 94305-5332 USA
}

\begin{abstract}
Major changes in cytoarchitecture and gene expression were induced in short-term heterokaryons. When human hepatocytes were fused with mouse muscle cells, the hepatocyte Golgi apparatus changed from its usual polar location to a uniformly circumnuclear location typical of striated muscle. Human liver albumin ceased to be expressed, and expression of the human muscle cell-surface antigen 5.1H11 was induced without DNA replication or cell division. Coexpression of liver and muscle proteins was rarely observed. These novel findings provide insight into the regulation of gene expression and the targeting and localization of organelles with a central role in cell polarity, intracellular transport, and secretion.
\end{abstract}

[Key Words: Muscle; liver; Golgi apparatus; gene expression; somatic cell hybrids; differentiation]

Received November 16, 1987; revised version accepted January 25, 1988.

To understand the regulation of tissue-specific genes in differentiated cells, a number of approaches are being employed. The transfection of DNA into mammalian cultured cells has been particularly useful in the analysis of gene structure and function. Such studies have helped to define the cis-acting DNA sequences that regulate tissue-specific gene expression. These sequences can, in turn, be used in some cases to purify the transacting factors that act directly to alter their expression (Kadonaga and Tjian 1986). However, a transfected gene differs from its endogenous counterpart in its responsiveness to regulatory factors (Robins et al. 1982; Weintraub 1985). This has been demonstrated most recently in experiments in which stably transfected prolactin genes, but not their endogenous counterparts, were activated in heterokaryons (Lufkin and Bancroft 1987). An understanding of the mechanisms underlying the regulation of endogenous genes should provide insight into the derivation and maintenance of differentiated cells during development.

Of central importance to the function of the differentiated cell is the location and interaction of organelles that direct intracellular traffic. In most animal cells, the Golgi apparatus and microtubule organizing center (MTOC) are colocalized toward one side of the nucleus

${ }^{2}$ Current address: Department of Medicine, Division of Oncology, Stanford University Medical Center, Stanford, California 94305 USA. ${ }^{3}$ Current address: Department of Molecular and Cellular Biology $308 \mathrm{BSW}$, University of Arizona, Tucson, Arizona 85721 USA. at the centrioles of the centrosome (Rogalski and Singer 1984). This probably provides the polarity necessary for mitosis and motility (Singer and Kupfer 1986). In contrast, in differentiated striated muscle cells where this type of polarity is not required, the centrioles appear to be nonfunctional and the Golgi and MTOC have a different location, the vicinity of the nuclear membrane (Tassin et al. 1985a,b; Kronebusch and Singer 1987). Thus, in muscle, the factor(s) that targets or localizes the Golgi and MTOC is dissociated from the centrioles. In addition, the nature of the interaction between the MTOC and Golgi is altered (Louvard et al. 1982; Rogalski and Singer 1984; Tassin et al. 1985b).

Heterokaryons provide one approach to studying the regulation of endogenous genes and the targeting of organelles during differentiation (Blau et al. 1983, 1985). Because the nuclei in heterokaryons, or short-term nondividing somatic cell hybrids, remain separate and intact, the interactions between two genomes derived from cells of different functional states can be examined within a common cytoplasm. Our laboratory has used heterokaryons previously to demonstrate that nine different endogenous muscle genes can be activated in a wide range of nonmuscle cell types in response to transacting factors present in muscle cells (Blau et al. 1983, 1985; Chiu and Blau 1984, 1985; Hardeman et al 1986; Pavlath and Blau 1986). Our findings have been corroborated and extended by others using similar muscle heterokaryons (Wright 1984a,b; Clegg and Hauschka 1987) and heterokaryons produced with other cell types (Baron 
and Maniatis 1986; Enoch et al. 1986). These observations demonstrate that the heterokaryon state provides an experimental system that is well suited to the study of cellular factors that mediate the selective expression or repression of endogenous genes which accompanies cell specialization.

In the present study, for the first time we addressed questions regarding the fate of the nonmuscle cell type after fusion with a muscle cell. In the course of cell specialization during the development of the organism, cells make a choice and the expression of different differentiated states is generally mutually exclusive. We determined whether this was also the case in heterokaryons by examining whether two differentiated phenotypes were coexpressed in the same cell. Toward this end, we monitored the expression of both muscle and liver gene products and the distribution of the Golgi apparatus, which mediates their intracellular transport. Our results demonstrate that muscle components alter hepatocyte gene expression and induce major changes in cytoarchitecture involving the relocation of organelles of central importance to cell polarity, intracellular transport, and secretion.

\section{Results}

The hepatocyte Golgi distribution changes to a muscle Golgi distribution

The Golgi apparatus has a characteristic distribution that differs between differentiated striated muscle cells and other animal cell types (Tassin et al. 1985a,b; Kronebusch and Singer 1987). In hepatocytes, like undifferentiated myoblasts, the Golgi is asymmetrically localized toward one pole of the cell (Fig. 1A), whereas in differentiated skeletal muscle cells the Golgi is compactly circumnuclear and located in close proximity to the nuclear envelope (Tassin et al. 1985b). Heterokaryons were formed by fusing human hepatocytes of the Hep G2 line and mouse muscle $\mathrm{C} 2 \mathrm{C} 12$ cells. Individual cells were analyzed to determine whether hepatocyte nuclei contained in a heterokaryon retained a Golgi distribution that was typical of hepatocytes or changed to one typical of striated muscle. For this purpose we used an antibody to a Golgi enzyme, galactosyl transferase, which is localized in the trans cisternae of the Golgi stack and readily visualized by immunofluorescence (Berger et al. 1981; Berger and Hesford 1985; Lucocq et al. 1987).

Two types of circumnuclear Golgi distribution were detected in the 115 heterokaryons analyzed 6 days after fusion. A compact circumnuclear Golgi, similar to that observed in differentiated skeletal muscle cells, was found in the vicinity of all nuclei in heterokaryons that contained more muscle than hepatocyte nuclei (Fig. 2A). This compact circumnuclear Golgi distribution was not due to constraints in organelle movement imposed by the elongated shape of the differentiated muscle cell. It was also observed in large, amorphous heterokaryons that contained greater numbers of muscle than hepatocyte nuclei (Fig. 2B). The second type of Golgi distribution that was observed in heterokaryons was also circumnuclear but diffuse in appearance (Fig. 2C). This diffuse circumnuclear distribution was typical of
Figure 1. The hepatocyte Golgi apparatus is polar. In greater than $98 \%$ of individual hepatocytes, the Golgi is oriented at one side of the nucleus $(A)$. In hepatocytes fused to themselves as homokaryons, the Golgi typically aggregates and retains a polar distribution at one end of the multinucleated cell $(B)$. The same cells are shown stained with Hoechst 33258 to show nuclei (left) and by immunofluorescence with an antibody to galactosyl transferase to show the position of the Golgi apparatus (right). Magnification, $530 \times$.
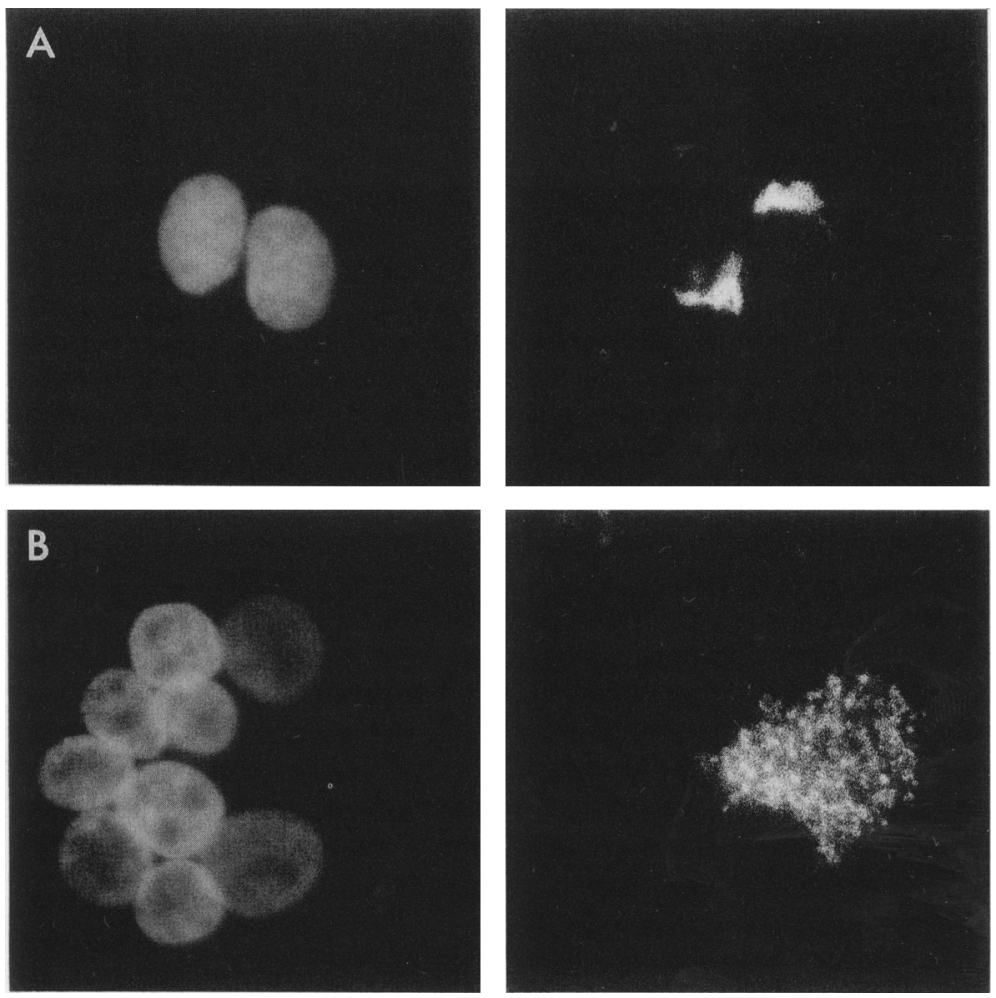
Miller et al.
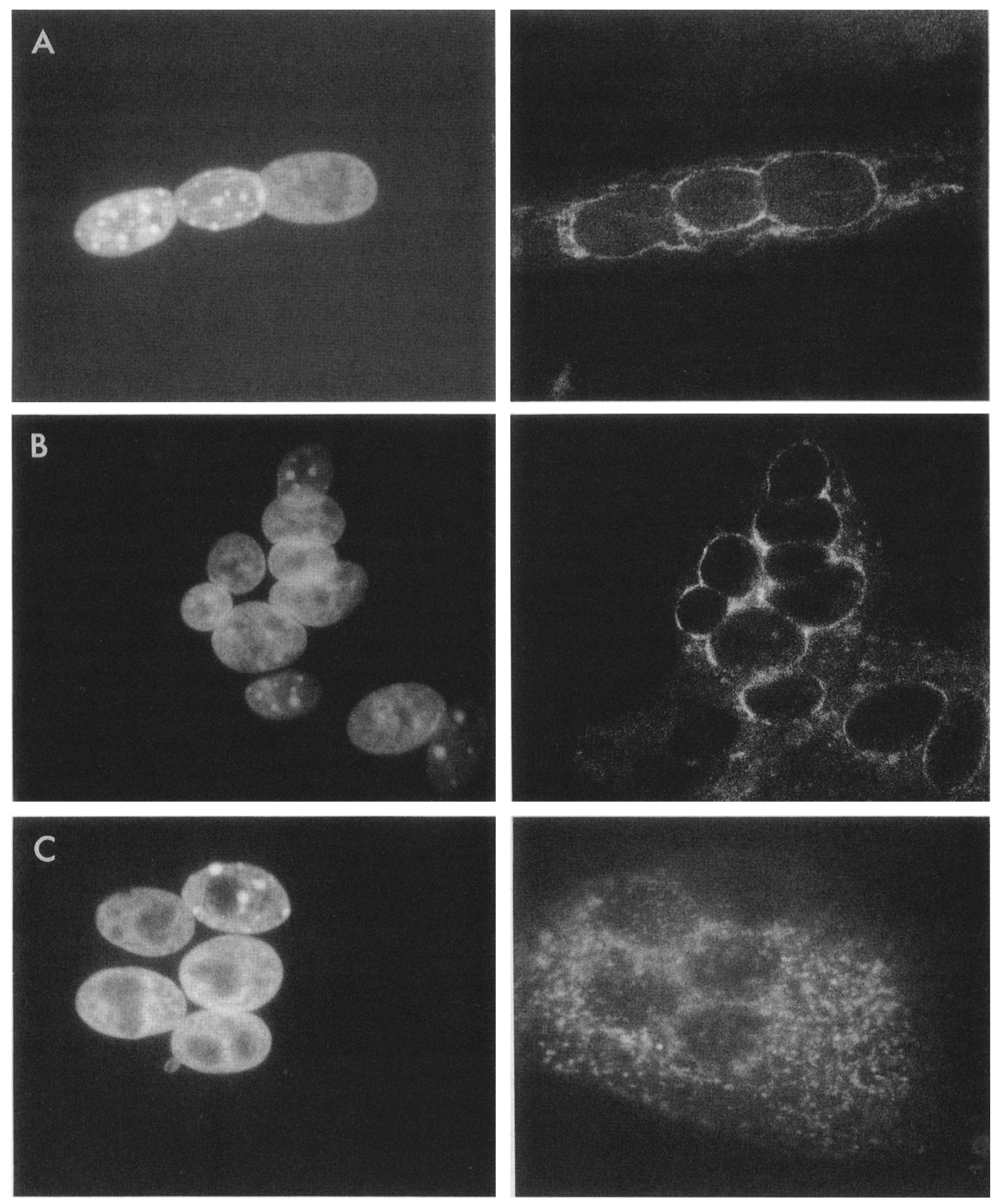

Figure 2. The hepatocyte Golgi apparatus changes from a polar to a circumnuclear distribution after fusion with muscle to form heterokaryons. Heterokaryons with an increased proportion of muscle nuclei have a compact circumnuclear Golgi typical of striated muscle, regardless of whether the cell shape is elongated $(A)$ or amorphous $(B)$. Heterokaryons with an equal or increased proportion of nonmuscle nuclei have a diffuse circumnuclear Golgi $|C|$. The same cells are shown stained with Hoechst 33258 to distinguish punctate mouse muscle and uniform human hepatocyte nuclei (left) and by immunofluorescence with an antibody to galactosyl transferase to show the position of the Golgi apparatus (right). The heterokaryon in $A$ has a total of two mouse and one human nuclei; $B$ is part of a heterokaryon with eight mouse and seven human nuclei; and $C$ is a heterokaryon with one mouse and four human nuclei. Magnification, $425 \times$.

heterokaryons that contained a greater number of hepatocyte nuclei, or an equivalent number of nuclei of each cell type.

Both types of circumnuclear Golgi distribution observed in heterokaryons contrasted sharply with the polar distribution observed in Hep G2 cells alone (Fig. 1). The change from a hepatocyte-like to a muscle-like Golgi distribution could not be induced by growth arrest or the formation of a multinucleated Hep G2 cell. Hep G2 cells were fused to themselves with polyethylene glycol (PEG) and maintained for 6 days in the presence of the DNA synthesis inhibitor cytosine arabinoside /arac), a treatment that eliminates dividing cells. The Golgi apparatus in the resulting homokaryons was polar, forming a single aggregate at one end of the cell. In contrast, the presence of a single muscle nucleus resulted in a major disruption of the characteristic polar Golgi aggregate derived from multiple fused hepatocytes. This is shown most clearly by the strikingly different Golgi distributions in homokaryons (Fig. 1B) and in a heterokaryon containing four hepatocyte nuclei and only one muscle nucleus (Fig. 2C).

\section{Influence of gene dosage on the Golgi distribution}

The type of circumnuclear Golgi distribution observed 
in heterokaryons was influenced by the relative numbers of muscle and hepatocyte nuclei, or the gene dosage contributed by each cell type. As shown in the histogram in Figure 3, a compact circumnuclear Golgi distribution was found in $68 \pm 8 \%$ of heterokaryons in which muscle nuclei predominated. In contrast, only $22 \pm 5 \%$ of heterokaryons that contained equivalent numbers of muscle and hepatocyte nuclei, or in which there was an increased proportion of hepatocyte nuclei, had a compact circumnuclear 'Golgi, whereas $70 \pm 5 \%$ had a diffuse circumnuclear Golgi. A polar Golgi typical of hepatocytes alone was rarely observed. Less than $10 \%$ of all heterokaryons had a polar Golgi. These-results suggest that muscle cell components dictate in a dosagedependent manner the distribution of a secretory organelle in heterokaryons containing muscle and hepatocyte nuclei.

Activation of human muscle $5.1 \mathrm{H} 11$ and extinction of human albumin

We examined the expression of the human liver protein albumin and the human muscle cell-surface antigen $5.1 \mathrm{H} 11$ in 2687 individual heterokaryons. Examples of heterokaryons that expressed either albumin or $5.1 \mathrm{H} 11$ 6 days after fusion are shown in the same field in Figure $4(\mathrm{~A}-\mathrm{D})$. The expression of albumin and $5.1 \mathrm{H} 11$ was monitored simultaneously in heterokaryons by double immunofluorescence microscopy using species-specific antibodies. In the heterokaryon on the right side of the field, only $5.1 \mathrm{H} 1 \mathrm{l}$ is detected, and its distribution is typical of a cell-surface antigen (Fig. $4 \mathrm{C}$ ). Because $5.1 \mathrm{H1}$ is never detected in either cell type alone or in homokaryons, its expression in heterokaryons appears to result from gene activation by trans-acting regulators (Chiu and Blau 1984, 1985). In the heterokaryon on the left side of the field, only albumin is expressed, and it is localized in the vicinity of the Golgi apparatus (Fig. 4D). Albumin is a secreted protein that exits the cell within $30 \mathrm{~min}$ after its synthesis (Feldhoff et al. 1977). To detect albumin in our experiments, heterokaryons were exposed for several hours prior to fixation to the ionophore monensin, which blocks exocytosis in the Golgi apparatus (Tartakoff 1983). Therefore, the albumin detected in the experiments presented here was newly synthesized. Accordingly, the heterokaryon on the left side of the micrograph (Fig. 4D) is an example of one in which the translation of mRNA encoding liver albumin continued to occur for 6 days after fusion with muscle.

An example of a heterokaryon that expressed both human muscle $5.1 \mathrm{H} 11$ and human albumin is shown in Figure $4(E-H)$. This was a very rare event; only 28 heterokaryons coexpressed both the muscle and liver proteins, a frequency of approximately $1 \%$. Of these, only four contained a single human nucleus; the others, like the one shown in Figure $4(\mathrm{E}-\mathrm{H})$, had multiple human nuclei. Thus, only in four cases, or $0.2 \%$ of all heterokaryons analyzed, did the two types of proteins definitively derive from the same nucleus.

We examined the expression of the human muscle and liver proteins in heterokaryons over time. Duplicate

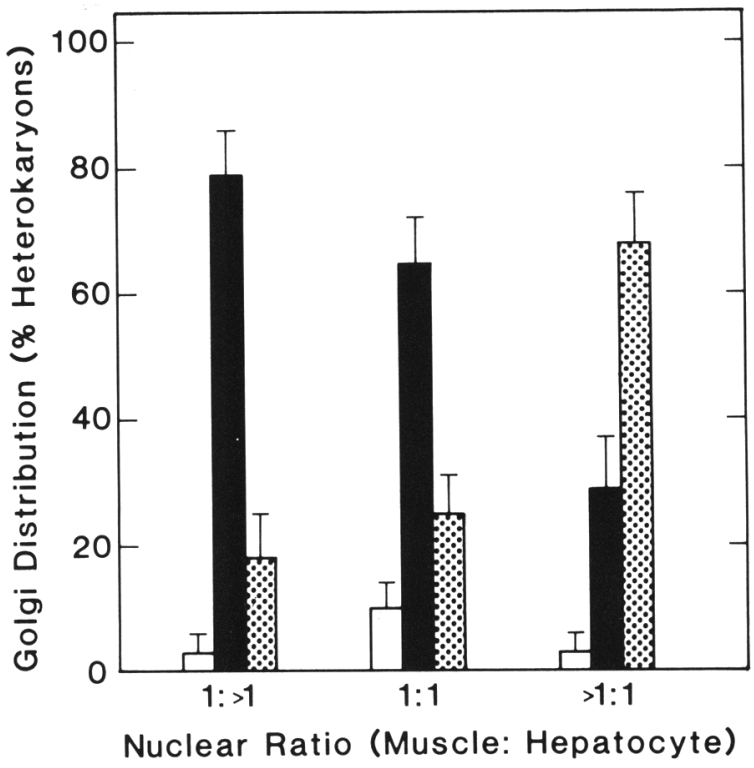

Figure 3. The Golgi distribution is influenced by gene dosage in heterokaryons. The frequency of polar $(\square)$, diffuse circumnuclear ( $\square$ ), and compact circumnuclear (國) distributions of the Golgi apparatus was correlated with the ratio of muscle to hepatocyte nuclei. A total of 115 heterokaryons was analyzed. The data are expressed as the mean \pm the standard error of the proportion.

dishes of heterokaryons, control Hep G2, and C2C12 homokaryons were assayed at $0.25,2,4,6,8$, and 11 days after fusion for both $5.1 \mathrm{Hll}$ and for albumin. As shown in Figure 5, the activation of the human muscle antigen $5.1 \mathrm{H} 11$ was first detectable on day 2 , and the frequency with which it was expressed increased thereafter, reaching a maximum of $36 \pm 2 \%$ of all heterokaryons by day 6 . In contrast, the extinction of human albumin in heterokaryons was rapid. Only $65 \pm 3 \%$ of all heterokaryons contained detectable amounts of albumin $6 \mathrm{hr}$ after fusion, the first time point that could be assayed. The marked reduction in the number of heterokaryons that produced albumin was not a direct result of the fusion procedure or the culture conditions, because greater than $95 \%$ of homokaryon Hep G2 cells stably synthesized albumin for the duration of the time course. At any given time point, the frequency of heterokaryons that coexpressed both liver and muscle proteins was low. Albumin expression in heterokaryons continued to decline steadily. By day 11 after fusion, $99 \%$ of the heterokaryons analyzed no longer produced albumin. Thus, virtually all hepatocytes in heterokaryons extinguished the synthesis of human liver albumin, and in one third of the heterokaryons the human muscle gene for $5.1 \mathrm{H} 11$ was activated.

\section{Influence of gene dosage on $5.1 \mathrm{H} 11$ and albumin expression}

The kinetics of muscle $5.1 \mathrm{H} 11$ expression by hepatocyte nuclei were correlated with the proportion of muscle nuclei in heterokaryons. Heterokaryons were pooled 
Miller et al.
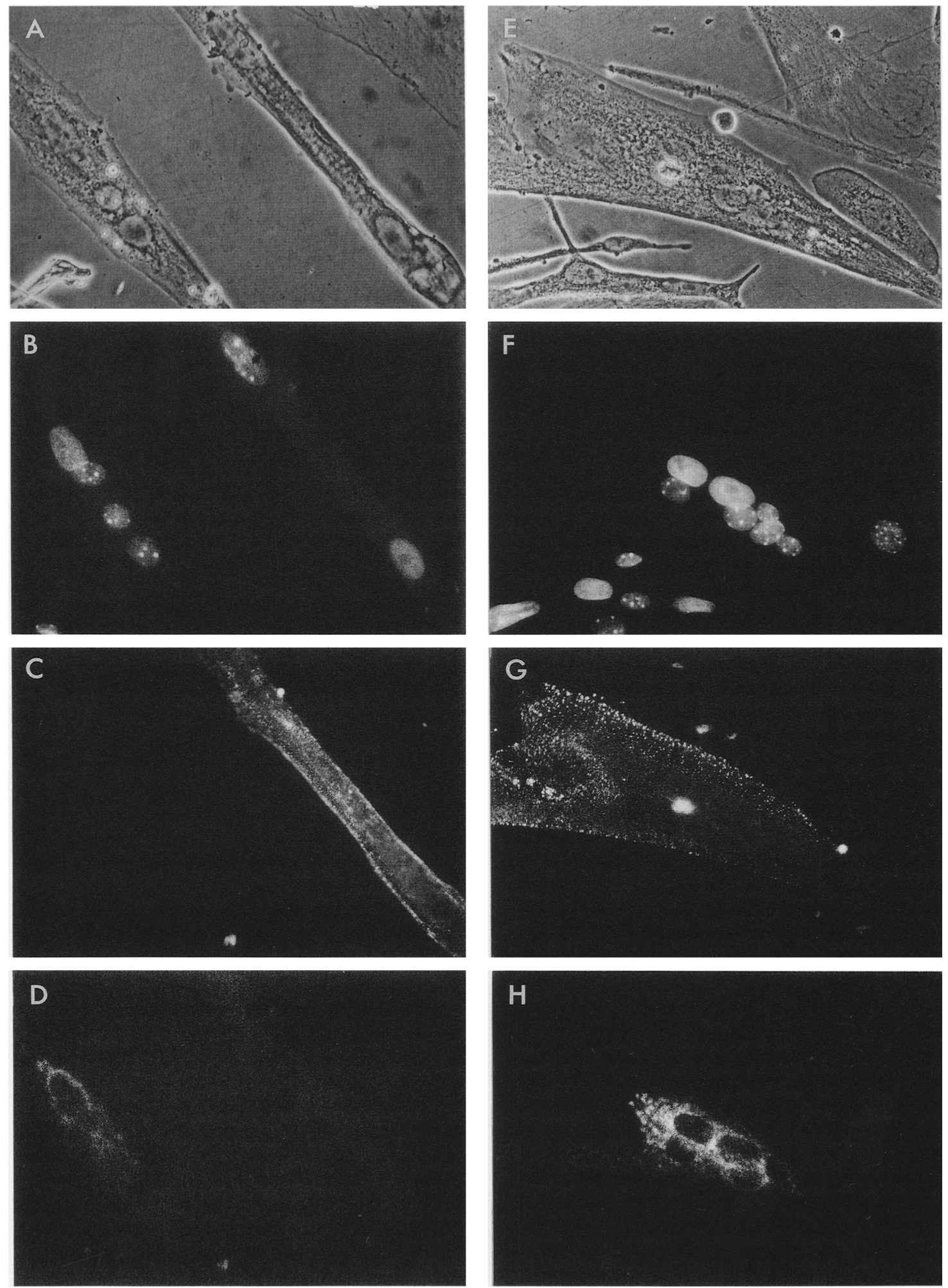

Figure 4. $(A-D)$ Two heterokaryons are shown in the same field that expressed either the liver protein albumin (left) or the muscle cell-surface antigen $5.1 \mathrm{H} 11$ (right) 6 days after fusion. $(E-H)$ A single heterokaryon that coexpressed both human muscle $5.1 \mathrm{H} 11$ and liver albumin. $(A, E)$ Heterokaryons in phase-contrast microscopy; $(B, F)$ the same heterokaryons with Hoechst fluorescence to distinguish human (uniform) or mouse (punctate) nuclei; $(C, G)$ Texas Red immunofluorescence to detect the muscle cell-surface antigen, $5.1 \mathrm{H} 11 ;(D, H)$ fluorescein immunofluorescence to detect liver albumin. The position of the Golgi apparatus, determined by the distribution of albumin, is not as compactly circumnuclear as that in Fig. 2. This is due, in part, to the presence of albumin in the rough endoplasmic reticulum and secretory vesicles and to the effects of monensin, which was used only to visualize albumin. Monensin inhibits secretion and causes dramatic swelling of the Golgi in both muscle and nonmuscle cells (Tassin et al. 1985b). Magnification, $300 \times$. 
Figure 5. Time course of muscle 5.1H11 and liver albumin expression in heterokaryons. The frequency of expression in heterokaryons of 5.1H11 (-- - ), albumin (-—) or both $5.1 \mathrm{H} 11$ and albumin $(\cdots \cdot \cdots)$ is shown. Control hepatocytes fused to themselves as homokaryons continue to express albumin $(-\Delta-)$. More than 200 heterokaryons were analyzed per dish; duplicate dishes were analyzed at each time point. The data are expressed as the mean \pm the standard error of the proportion.

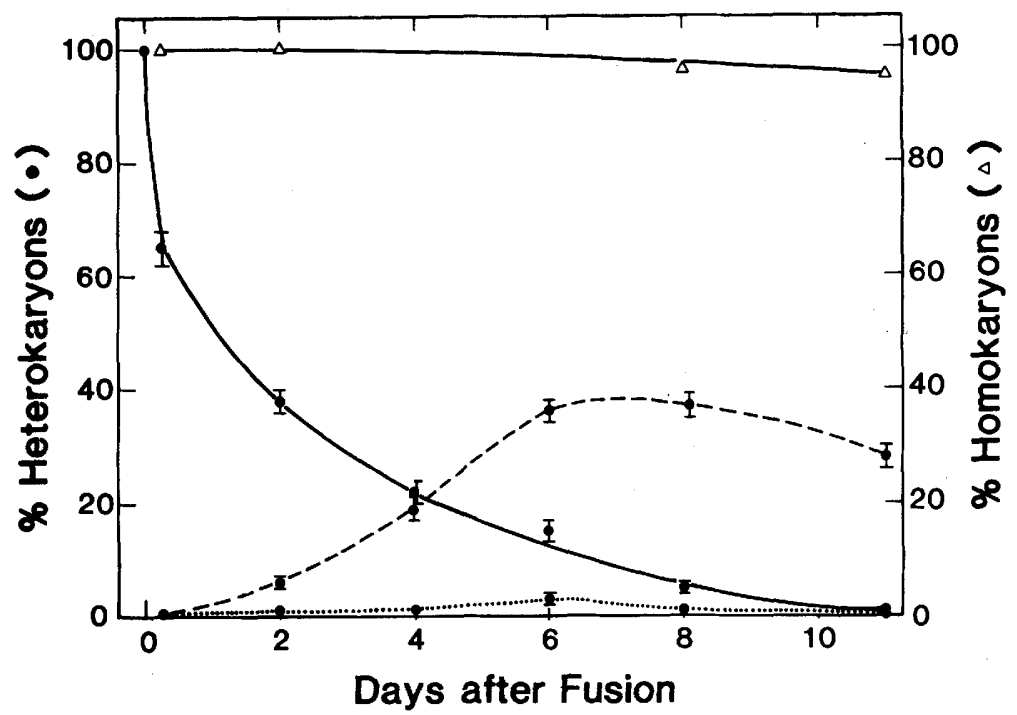

DNA replication is not required for $5.1 \mathrm{H} 11$ activation, albumin extinction, or Golgi redistribution

We determined at the single-cell level whether DNA replication was required for the activation of $5.1 \mathrm{H} 11$, the extinction of albumin, or the change in Golgi distribution in heterokaryons. We had shown previously that DNA synthesis could be inhibited by $98 \%$ in heterokaryons produced with fibroblasts without affecting the frequency of $5.1 \mathrm{Hl} 1$ activation (Chiu and Blau 1984). The slower kinetics of expression of $5.1 \mathrm{H} 11$ in heterokaryons containing hepatocytes suggested that the mechanism of activation might differ from that in fibroblasts (Blau et al. 1985). Possibly, changes in chromatin structure associated with DNA replication occurred during this period of time. To address this point at the single-cell level, hepatocytes were exposed to the DNA synthesis inhibitor, ara-c, for $24 \mathrm{hr}$ prior to and continuously after fusion with muscle cells. Six days after fusion, the cells were assayed and compared with controls.

A total of 957 individual heterokaryons were analyzed for DNA synthesis by autoradiography and for the expression of $5.1 \mathrm{H1} 1$ and albumin by double immunofluorescence. As shown in Table 1 , the presence or absence of ara-c did not significantly alter the frequency of expression of either protein. It did, however, have a significant effect on the level of DNA synthesis. In contrast to controls, none of the hepatocyte heterokaryons that activated $5.1 \mathrm{H} 1 \mathrm{l}$ and less than $10 \%$ of the heterokaryons that extinguished albumin had any detectable DNA synthesis in the presence of ara-c. Not a single hepatocyte nucleus inside a heterokaryon underwent a complete round of DNA replication in the presence of ara-c. ara-c was also present in the experiments in which the Golgi changed from a polar to a circumnuclear location. These data suggest that DNA replication is not a prerequisite for $5.1 \mathrm{H} 1 \mathrm{l}$ activation, albumin extinction, or the change in Golgi distribution that occurs in heterokaryons. 




Figure 6. Time course of effect of gene dosage on albumin or $5.1 \mathrm{H} 11$ expression in heterokaryons. A total of 2687 individual heterokaryons were grouped according to nuclear composition, or the number of mouse and human nuclei they contained. Five different groups were established that included the following ratios of mouse (muscle) to human (hepatocyte) nuclei: $1:>2(\square) ; 1: 2(1: x$ where $1<x \leqslant 2)(\mathbb{Q}) ; 1: 1$ (圆); $2: 1(x: 1$, where $1<x \leqslant 2)$ (网); and $>2: 1$ (D). The proportion of heterokaryons with different nuclear compositions gave a Gaussian distribution with the $1: 1$ ratio most frequent. The data are expressed as the mean \pm the standard error of the proportion.

\section{Discussion}

In this study we address questions regarding the fate of the nonmuscle cell in heterokaryons. Previous experiments had demonstrated that upon fusion with muscle cells a pattern of gene expression typical of muscle could be induced in a range of mesodermal, ectodermal, and endodermal cell types, including fibroblasts, keratinocytes, adrenal cells, neural cells, and hepatocytes, that normally never express muscle genes (Blau et al. 1983, 1985; Wright 1984a,b; Hardeman et al. 1986). In this report, the possibility that muscle factors alter the expression of the other phenotype-in this case, the hepatocyte-was examined. We determined the influence of muscle cell components on hepatic gene expression and cytoarchitecture, in particular, the disposition of the Golgi apparatus, an organelle with a central role in cell polarity, intracellular transport, and secretion.

\section{The change in Golgi location signifies a maior change in cytoarchitecture}

After fusion and heterokaryon formation, the Golgi changed from its typical polar location at one side of the hepatocyte nucleus to a uniform circumnuclear location characteristic of striated muscle cells. The change in Golgi location was not caused by growth arrest or the multinucleated state. In homokaryons of Hep G2 cells, the Golgi derived from several nuclei were found clustered together at one end of the cell in a single aggregate (Fig. 1B), similar to the aggregates of centrosomes described by others in homokaryons of either hamster kidney BHK21 cells or HeLa cells (Wang et al. 1979; Tassin et al. 1985a). Instead, the circumnuclear location of the Golgi appears to be a specific property of differentiated striated muscle cells, as it is also found in mononucleated cardiac but not smooth muscle cells (Kronebusch and Singer 1987).

The change from a polar to a circumnuclear Golgi has broad implications for intracellular organization. The Golgi plays a central role in directing macromolecular traffic within the cell and in determining cell polarity. It is essential to the intracellular transport and processing of membrane components such as muscle $5.1 \mathrm{H} 11$ and secretory proteins such as liver albumin. In dividing cells, like myoblasts or hepatocytes, the Golgi apparatus and the MTOC from which microtubules originate are colocalized toward one side of the nucleus at the centro-



Figure 7. Influence of nuclear composition on the kinetics of albumin extinction and $5.1 \mathrm{H} 11$ expression. The same heterokaryons analyzed in Fig. 6 were combined into five groups. (Top two groups): (-O-) Increased or equivalent proportion of muscle nuclei $(\geqslant 1: 1) ;(\cdots \bullet \cdots)$ increased proportion of hepatocyte nuclei $(1:>1)$. (Bottom three groups): $(-\circ-)$ increased proportion of muscle nuclei $(>1: 1)$; $(--\square--)$ equivalent nuclear input $(1: 1),(\cdots \bullet \cdots)$ increased proportion of hepatocyte nuclei $(1:>1)$. The data are expressed as the mean \pm the standard error of the proportion. 
Altered cytoarchitecture in heterokaryons

Table 1. Activation of $5.1 \mathrm{H11}$ and extinction of albumin in heterokaryons occurs in the absence of DNA replication

\begin{tabular}{|c|c|c|c|c|c|c|c|}
\hline \multirow[b]{2}{*}{ Ara C } & \multirow{2}{*}{$\begin{array}{l}\text { Total } \\
\text { heterokaryons } \\
\text { scored }\end{array}$} & \multirow{2}{*}{$\begin{array}{l}\text { Heterokaryons } \\
\text { that activated } \\
5.1 \mathrm{H} 11 \\
(\%)\end{array}$} & \multirow{2}{*}{$\begin{array}{l}\text { Heterokaryons } \\
\text { that extinguished } \\
\text { albumin } \\
(\%)\end{array}$} & \multicolumn{2}{|c|}{$\begin{array}{l}\text { Heterokaryons that } \\
\text { activated } 5.1 \mathrm{H} 11 \\
\text { and have labeled } \\
\text { human nuclei }(\%)\end{array}$} & \multicolumn{2}{|c|}{$\begin{array}{l}\text { Heterokaryons that } \\
\text { extinguished albumin } \\
\text { and have labeled } \\
\text { human nuclei }(\%)\end{array}$} \\
\hline & & & & $>10$ grains & $>50$ grains & $>10$ grains & $>50$ grains \\
\hline- & 461 & $23 \pm 2$ & $92 \pm 1$ & $23 \pm 4$ & $6 \pm 2$ & $40 \pm 2$ & $16 \pm 2$ \\
\hline+ & 496 & $19 \pm 2$ & $90 \pm 1$ & 0 & 0 & $7 \pm 1$ & 0 \\
\hline
\end{tabular}

Heterokaryons were scored 6 days after fusion. A human hepatocyte nucleus that replicated one-fifth of its genomic DNA could be detected by our methods (Chiu and Blau 1984). A nucleus was scored as labeled if it had 10 or more silver grains over it, a level threefold above background. A nucleus with more than 50 grains over it was scored as heavily labeled and considered likely to have undergone a complete round of replication. The results were expressed as the mean \pm standard error of the proportion.

some, composed of a pair of centrioles and pericentriolar material (Tassin et al. 1985a; Petit et al. 1986; Singer and Kupfer 1986). In contrast, in differentiated striated muscle cells, the Golgi apparatus and MTOC are no longer centered on the centrioles but circle the nucleus at a uniform distance of $0.2 \mu \mathrm{m}$ (Tassin et al. 1985b). Indeed, in differentiated skeletal muscle cells, unlike most animal cells, the centrioles appear to be reduced in number, dispersed, and probably nonfunctional (Tassin et al. 1985a). The finding that the centrioles can be dissociated from the MTOC and Golgi suggests that their primary role is to establish the polarity necessary for elaborating astral microtubules for mitosis and cell movement (Singer and Kupfer 1986). Like muscle, cells that do not require such polarity have a different target for these organelles, the vicinity of the nuclear membrane. The relationship between the Golgi and the MTOC is also altered in differentiated muscle. A nocodazole-induced depolymerization of microtubules leads to a reversible dispersion of the polar but has no effect on the circumnuclear Golgi apparatus (Louvard et al. 1982; Rogalski and Singer 1984; Tassin et al. 1985b).

The heterokaryon studies described here demonstrate that by fusing disparate cell types, the function and interrelationship of cell organelles can be altered dramatically. This change occurs within a few days in the absence of cell division or DNA replication. These results raise the intriguing possibility that there may be one or more muscle components or trans-acting factors capable of targeting the MTOC and Golgi to the nuclear periphery, independent of the centrioles. By liposome or red blood cell-mediated fusion, osmotic lysis of pinocytic vesicles, or cellular microinjection (Capecchi 1980; Szoka et al. 1981; Okada and Rechsteiner 1982; Godfrey et al. 1983), it should now be possible to introduce muscle macromolecules into the responsive hepatocytes described here and test this hypothesis directly.

\section{Muscle proteins are expressed and liver proteins are extinguished}

Our results suggest that in heterokaryons, as in the developing organism, the expression of one phenotype precludes the expression of the other. The coexpression of the human liver product albumin and the novelly induced human muscle cell-surface antigen $5.1 \mathrm{H} 11$ in the same cell occurred with a frequency of $1 \%$ in the 2687 heterokaryons analyzed. Thus, it appears that the simultaneous expression of liver and muscle products within a heterokaryon is the exception to the rule and may never occur at the transcriptional level in a single nucleus.

Gene dosage influenced the time course of extinction and activation in heterokaryons, suggesting that the balance of positive and negative factors contributed by muscle and liver cell types was critical. Gene dosage also influenced the ultimate frequency of activation in heterokaryons with hepatocytes, in contrast to previous findings with fibroblasts (Pavlath and Blau 1986). Extinction, on the other hand, was ultimately observed in virtually all heterokaryons, even those in which hepatocyte nuclei outnumbered muscle nuclei, suggesting that the continuous production of factors only by muscle was sufficient. Although the extinction of albumin is likely to be mediated, in part, by post-transcriptional mechanisms (Clayton et al. 1985a,b; Bachmair et al. 1986), transcriptional mechanisms presumably play an important role. That gene loci isolated from fibroblasts are capable of stably producing trans-acting repressors of liver functions has been demonstrated by both Killary and Fournier (1984) and Petit et al. (1986). To date, this has been achieved by chromosome transfer, not by transfection of naked DNA, possibly because an intact fibroblast chromatin structure is required. Presumably, a similar trans-dominant locus in muscle cells could cause the extinction of albumin seen in our experiments, despite the presence of positive regulatory factors contributed by hepatocytes (Courtois et al. 1987).

Studies that examine the requirements for the expression of endogenous genes, like those presented here, are central to understanding differentiation. Although much has been learned regarding tissue-specific gene expression from the transfection of well-characterized DNA sequences, it is clear that the heritable changes associated with the stable integration of transfected genes and the heritable changes that accompany determination during development differ. For example, in heterokaryons produced by fusing pituitary cells and fibroblasts stably transfected with a silent prolactin gene promoter construct, the transfected but not the endogenous prolactin gene was activated (Lufkin and Bancroft 1987). The need to study the regulation of endogenous genes is underscored by these and other findings (Robins et al. 1982; Weintraub 1985). The heterokaryons described 
here provide a means for inducing changes in endogenous gene expression that can be analyzed at a molecular level. The elucidation of the different requirements for the extinction and activation of endogenous genes in a specialized cell type such as the hepatocyte should provide insight into the derivation and maintenance of that phenotype in the course of human development.

\section{Methods \\ Cells and culture conditions}

The mouse muscle cell line $\mathrm{C} 2 \mathrm{C} 12$ has been described previously (Yaffe and Saxel 1977; Blau et al. 1983). Hepatocytes (Hep G2), a nontumorigenic human hepatoma cell line, were a generous gift of Dr. Barbara Knowles (Aden et al. 1979). These cells stably express albumin in addition to 16 other liver-specific proteins (Knowles et al. 1980). Hep G2 cells were grown in minimal Eagle's medium (MEM) with $10 \%$ fetal calf serum but plated in $\mathrm{C} 2 \mathrm{Cl} 2$ fusion medium (FM) containing Dulbecco's modified Eagle's medium (DMEM) with 2\% horse serum for homokaryon and heterokaryon studies.

\section{Production of heterokaryons}

Heterokaryons and homokaryons were produced as described previously (Blau et al. 1983; Chiu and Blau 1984). Mouse muscle $\mathrm{C} 2 \mathrm{C} 12$ cells were fused with $\mathrm{Hep} \mathrm{G} 2$ hepatocytes using PEG $1000(\mathrm{BDH})$. Except in studies of DNA synthesis (see below), ara-c, $10^{-5} \mathrm{M}$ was routinely added $24 \mathrm{hr}$ after fusion together with ouabain, $10^{-5} \mathrm{M}$ to eliminate unfused and proliferating cells.

\section{Immunofluorescence assay of Golgi apparatus}

To study the distribution of the Golgi apparatus, an affinity-purified rabbit polyclonal antibody $\left(\mathrm{O}_{12}\right)$ to the human Golgi enzyme galactosyl transferase was used, which was the generous gift of Dr. Eric Berger (Berger et al. 1981; Berger and Hesford 1985). Monensin was not used in any experiments in which the Golgi distribution was analyzed with antibody $\mathrm{O}_{12}$. All procedures were carried out at room temperature unless otherwise noted. Homokaryon and heterokaryon cells were fixed in $1.5 \%$ formaldehyde in phosphate-buffered saline (PBS) for $15 \mathrm{~min}$, rinsed once with PBS, and incubated in $50 \mathrm{~mm}$ ammonium chloride in PBS for $10 \mathrm{~min}$, followed by one rinse with PBS. The cells were then permeabilized with $0.1 \%$ saponin in PBS for 1 min and washed three times with PBS. Fixed cells were incubated with the antibody to galactosyl transferase at a $1: 5$ dilution in $0.5 \%$ bovine serum albumin (BSA) in PBS for $30 \mathrm{~min}$. The cells were washed twice rapidly and then twice for $5 \mathrm{~min}$ each with $0.5 \%$ BSA and $0.5 \%$ Tween 20 in PBS. The cells were then incubated with a fluorescein-conjugated anti-rabbit IgG (Cappel Laboratories, Cooper Diagnostics, Inc., Malvern, Pennsylvania\}, diluted $1: 200$ in $0.5 \% \mathrm{BSA}$ in PBS for $30 \mathrm{~min}$, washed as before, and stained with Hoechst 33258 (Riedel-de Haën, Hannover, Germanyl. As a control for antibody specificity, replicate dishes were stained with antibody to galactosyl transferase that had been mixed previously with purified human galactosyl transferase (Dr. E. Berger) for 2 days at $4^{\circ} \mathrm{C}$. To reduce photobleaching of the fluorescein signal, the antioxidant, $n$-propyl gallate (Sigma Chemical Co., St. Louis, Missouri) was added at $2 \%(\mathrm{wt} / \mathrm{vol})$ in $30 \% 0.1 \mathrm{M}$ Tris, $\mathrm{pH} 9.0$, in glycerol, as described by Giloh and Sedat (1982).
Immunofluorescence assays for albumin and 5.1H11

To detect albumin, cells were incubated at $37^{\circ} \mathrm{C}$ in medium containing $10^{-6} \mathrm{M}$ monensin (Sigma) prior to fixation. Monensin is a carboxylic ionophore that blocks secretion in the Golgi by altering the $\mathrm{Na}^{+}-\mathrm{K}^{+}$balance essential to this step of the pathway (Tartakoff 1983). As a result, albumin accumulates inside the cell. In the absence of monensin, albumin was difficult to detect because it is secreted within $30 \mathrm{~min}$ of its synthesis (Feldhoff et al. 1977). At each time point $(0.25,2,4,6,8$, and 11 days after fusion), replicate dishes of fused cells were labeled live with monoclonal antibodies for the detection of the human muscle cell-surface antigen $5.1 \mathrm{Hl}$. Monoclonal antibody $5.1 \mathrm{Hl} 1$ was generously provided by Dr. Frank Walsh (Walsh and Ritter 1981) and used as described previously (Chiu and Blau 1985|. The cells were then fixed with $1 \%$ formaldehyde in PBS for $20 \mathrm{~min}$ at $37^{\circ} \mathrm{C}$. The cells were permeabilized with methanol $\left(-20^{\circ} \mathrm{C}\right)$ for $20 \mathrm{~min}$. Monensin was present immediately before and throughout the staining procedure until the cells were fixed, for a total time of approximately $4 \mathrm{hr}$.

Following fixation and permeabilization, cells were stained for albumin with polyclonal goat anti-human albumin IgG from Cappel Laboratories (Cooper Diagnostics). To remove antibodies that cross-reacted with mouse albumin, the antibody was affinity purified on a column of mouse albumin coupled to Sepharose. The affinity-purified antibody was shown to be human-specific by its immunofluorescent staining of human hepatoma cells (Hep G2) and lack of staining of mouse hepatoma cells (Hepalclc7, a gift of J. Whitlock). Both cell types were shown to contain albumin by labeling with a non-speciesspecific anti-albumin antibody (data not shown). The fixed cells were incubated with the anti-human albumin antibody in $1 \%$ $\mathrm{BSA}$ in PBS for $30 \mathrm{~min}$ at $37^{\circ} \mathrm{C}$. The dishes were washed twice rapidly and then twice for 5 min with $1 \%$ BSA and $0.5 \%$ Tween 20 in PBS. The cells were then incubated with a $1: 100$ dilution of a fluorescein-conjugated rabbit anti-goat IgG antibody (Zymed Laboratories, Inc., South San Francisco, California) in $1 \% \mathrm{BSA}$ in PBS for $30 \mathrm{~min}$ at $37^{\circ} \mathrm{C}$. The dishes were washed as described above and stained with Hoechst 33258 as described previously (Blau et al. 1983). In the presence of Hoechst 33258, the nuclei can be distinguished: mouse nuclei appear punctate and human nuclei appear homogeneously stained.

\section{Assay for DNA synthesis}

Hepatocytes were labeled with $\left[{ }^{3} \mathrm{H}\right]$ thymidine at $1.0 \mu \mathrm{Ci} / \mathrm{ml} \mid 83$ $\mathrm{Ci} / \mathrm{mmole}$, NEN, DuPont Co., Wilmington, Delaware) for the first $48 \mathrm{hr}$ after fusion. To inhibit DNA synthesis, cultures were exposed to $10^{-5} \mathrm{M}$ ara-c for $24 \mathrm{hr}$ prior to fusion and continuously thereafter until day 6 after fusion when the cells were fixed. Control cultures were not exposed to ara-c until $24 \mathrm{hr}$ after fusion; at this point, addition of the inhibitor served to prevent proliferation and cell overgrowth. We have shown previously that a $1-\mathrm{hr}$ exposure to ara-c at $10^{-5} \mathrm{M}$ reduces incorporation of $\left[{ }^{3} \mathrm{H}\right]$ thymidine into TCA-precipitable material to $1 \%$ of control levels (Chiu and Blau 1984). Duplicate dishes of cells that had been labeled with antibodies for detection of $5.1 \mathrm{H} 11$ and albumin were processed for autoradiography, as described previously (Chiu and Blau 1984).

\section{Statistics}

In all cases, the error indicates the standard error of the proportion calculated from the standard binomial equation: $\sqrt{\mathrm{pq} / \mathrm{n}}$. Where error bars do not overlap, differences are significant at the 0.05 level, using a two-sample Student's $t$ test. 


\section{Acknowledgments}

We are grateful to Dr. J. Singer for stimulating discussions, to Dr. E. Berger for the generous provision of antibody to galactosyl transferase, and to Dr. F. Walsh for the $5.1 \mathrm{H} 11$ antibody. We thank Drs. G. Crabtree, C. Goodman, and S. Pfeffer for comments on the manuscript and K. Bird for expert secretarial assistance. Graduate students, Emily Haliday and Jonathan Schuster, made important contributions to this work in its early phases. S.C.M. was supported by a postdoctoral fellowship from the National Institutes of Health $(\mathrm{NIH})$, and G.K.P. and B.T.B. by a predoctoral training grant (NIH GM07149). This work was funded, in part, by grants to H.M.B. from the National Science Foundation (DCB 8417089) and NIH (HD18179 and HD20203). H.M.B. is the recipient of an NIH Research Career Development Award (HD00580).

\section{References}

Aden, D.P., A. Fogel, S. Plotkin, I. Damjanov, and B.B. Knowles. 1979. Controlled synthesis of HBsAg in a differentiated human liver carcinoma-derived cell line. Nature 282: 615616.

Bachmair, A., D. Finley, and A. Varshavsky. 1986. In vivo halflife of a protein is a function of its amino-terminal residue. Science 234: 179-186.

Baron, M.H. and T. Maniatis. 1986. Rapid reprogramming of globin gene expression in transient heterokaryons. Cell 46: $591-602$.

Berger, E.G. and F.J. Hesford. 1985. Localization of galactosyland sialyltransferase by immunofluorescence: Evidence for different sites. Proc. Natl. Acad. Sci. 82: 4736-4739.

Berger, E.G., T. Mandel, and U. Schilt. 1981. Immunohistochemical localization of galactosyltransferase in human fibroblasts and HeLa cells. J. Histochem. Cytochem. 29: 364370.

Blau, H.M., C.-P. Chiu, and C. Webster. 1983. Cytoplasmic activation of human nuclear genes in stable heterokaryons. Cell 32: 1171-1180.

Blau, H.M., G.K. Pavlath, E.C. Hardeman, C.-P. Chiu, L. Silberstein, S.G. Webster, S.C. Miller, and C. Webster. 1985. Plasticity of the differentiated state. Science 230: 758-766.

Capecchi, M.R. 1980. High efficiency transformation by direct microinjection of DNA in cultured mammalian cells. Cell 22: $479-488$.

Chiu, C.-P. and H.M. Blau. 1984. Reprogramming cell differentiation in the absence of DNA synthesis. Cell 37: 879-887.

Chiu, C.-P. and H.M. Blau. 1985. 5-Azacytidine permits gene activation in a previously non-inducible cell type. Cell 40: $417-424$.

Clayton, D.F., A.L. Harrelson, and J.E. Darnell, Ir. 1985a. Dependence of liver-specific transcription on tissue organization. Mol. Cell. Biol. 5: 2623-2632.

Clayton, D.F., M. Weiss, and J.E. Darnell, Jr. 1985b. Liver-specific RNA metabolism in hepatoma cells: Variations in transcription rates and mRNA levels. Mol. Cell. Biol. 5: $2633-2641$.

Clegg, C.H. and S.D. Hauschka. 1987. Heterokaryon analysis of muscle differentiation: Regulation of the postmitotic state. I. Cell Biol. 105: 937-947.

Courtois, G., J.G. Morgan, L.A. Campbell, G. Fourel, and G.R. Crabtree. 1987. Interaction of a liver-specific nuclear factor with the fibrinogen and alpha 1-antitrypsin promoters. Science 238: 688-692.

Enoch, T., K. Zinn, and T. Maniatis. 1986. Activation of the human $\beta$-interferon genes requires an inducible factor. Mol. Cell. Biol. 6: $801-810$.

Feldhoff, R.C., J.M. Taylor, and L.S. Jefferson. 1977. Synthesis and secretion of rat albumin in vivo, in perfused liver, and in isolated hepatocytes. J. Biol. Chem. 252: 3611-3616.

Giloh, H. and J.W. Sedat. 1982. Fluorescence microscopy: Reduced photobleaching of rhodamine and fluorescein protein conjugates by $n$-propyl gallate. Science 217: 1252-1255.

Godfrey, W., B. Doe, and L. Wofsy. 1983. Immunospecific vesicle targeting facilitates microinjection into lymphocytes. Proc. Natl. Acad. Sci. 80: 2267-2271.

Hardeman, E.C., C.-P. Chiu, A. Minty, and H.M. Blau. 1986. The pattern of actin expression in human fibroblast $\times$ mouse muscle heterokaryons suggests that human muscle regulatory factors are produced. Cell 47: 123-130.

Kadonaga, J.T. and R. Tjian. 1986. Affinity purification of sequence-specific DNA binding proteins. Proc. Natl. Acad. Sci. 83: 5889-5893.

Killary, A.M. and R.E.K. Fournier. 1984. A genetic analysis of extinction: Trans-dominant loci regulate expression of liver-specific traits in hepatoma hybrid cells. Cell 38: $523-$ 534

Knowles, B.B., C.C. Howe, and D.P. Aden. 1980. Human hepatocellular carcinoma cell lines secrete the major plasma proteins and hepatitis B surface antigen. Science 209: 497-499.

Kronebusch, P.J. and S.J. Singer. 1987. The microtubule-organizing complex and the Golgi apparatus are co-localized around the entire nuclear envelope of interphase cardiac myocytes. I. Cell. Sci. 88: 25-34.

Louvard, D., H. Reggio, and G. Warren. 1982. Antibodies to the Golgi complex and the rough endoplasmic reticulum. I. Cell Biol. 92: 92-107.

Lucocq, J.M., E.G. Berger, and J. Roth. 1987. Detection of terminal $\mathrm{N}$-linked $\mathrm{N}$-acetylglucosamine residues in the Golgi apparatus using galactosyltransferase and endoglucosaminidase F/peptide $N$-glycosidase F: Adaptation of a biochemical approach to electron microscopy. J. Histochem. Cytochem. 35: $67-74$

Lufkin, T. and C. Bancroft. 1987. Identification by cell fusion of gene sequences that interact with positive trans-acting factors. Science 237: 283-286.

Okada, C.Y. and M. Rechsteiner. 1982. Introduction of macromolecules into cultured mammalian cells by osmotic lysis of pinocytic vesicles. Cell 29: 33-41.

Pavlath, G.K. and H.M. Blau. 1986. Expression of muscle genes in heterokaryons depends on gene dosage. I. Cell Biol. 102: $124-130$.

Petit, C., J. Levilliers, M.-O. Ott, and M.C. Weiss. 1986. Tissuespecific expression of the rat albumin gene: Genetic control of its extinction in microcell hybrids. Proc. Natl. Acad. Sci. 83: $2561-2565$.

Robins, D.M. I. Paek, P.H. Seeburg, and R. Axel. 1982. Regulated expression of human growth hormone genes in mouse cells. Cell 29: 623-631.

Rogalski, A.A. and S.J. Singer. 1984. Associations of elements of the Golgi apparatus with microtubules. /. Cell Biol. 99: $1092-1100$.

Singer, S.J. and A. Kupfer. 1986. The directed migration of eukaryotic cells. Annu. Rev. Cell Biol. 2: 337-365.

Szoka, F., K.-E. Magnusson, J. Wojcieszyn, Y. Hou, Z. Derzko, and $\mathrm{K}$. Jacobson. 1981. Use of lectins and polyethylene glycol for fusion of glycolipid-containing liposomes with eukaryotic cells. Proc. Natl. Acad. Sci. 78: 1685-1689.

Tartakoff, A.M. 1983. Perturbation of vesicular traffic with the carboxylic ionophore monensin. Cell 32: 1026-1028.

Tassin, A.-M., B. Maro, and M. Bornens. 1985a. Fate of micro- 


\section{Miller et al.}

tubule-organizing centers during myogenesis in vitro. I. Cell Biol. 100: 35-46.

Tassin. A.-M., M. Paintrand, E.G. Berger, and M. Bornens. 1985b. The Golgi apparatus remains associated with microtubule organizing centers during myogenesis. I. Cell Biol. 101: 630-638.

Walsh, F.S. and M.A. Ritter. 1981. Surface antigen differentiation during human myogenesis in culture. Nature 289: 6064.

Wang, E., J.A. Connolly, V.I. Kalnins, and P.W. Choppin. 1979. Relationship between movement and aggregation of centrioles in syncytia and formation of microtubule bundles. Proc. Natl. Acad. Sci. 76: 5719-5723.

Weintraub, H. 1985. Assembly and propagation of repressed and derepressed chromosomal states. Cell 42: 705-711.

Wright, W.E. 1984a. Induction of muscle genes in neural cells. J. Cell Biol. 98: 427-435.

Wright, W.E. 1984b. Expression of differentiated functions in heterokaryons between skeletal myocytes, adrenal cells, fibroblasts and glial cells. Exp. Cell Res. 151: 55-69.

Yaffe, D. and O. Saxel. 1977. Serial passaging and differentiation of myogenic cells isolated from dystrophic mouse muscle. Nature 270: 725-727. 


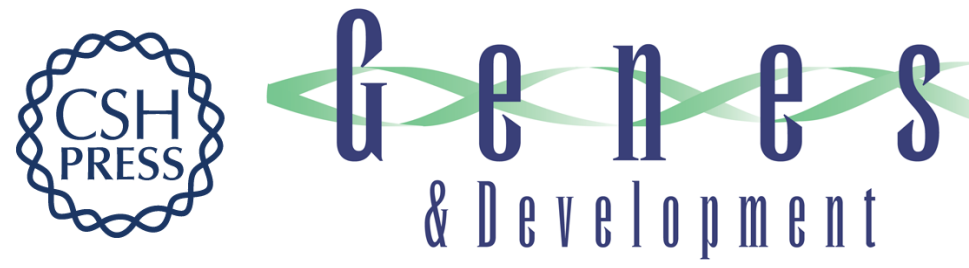

\section{Muscle cell components dictate hepatocyte gene expression and the distribution of the Golgi apparatus in heterokaryons.}

S C Miller, G K Pavlath, B T Blakely, et al.

Genes Dev. 1988, 2:

Access the most recent version at doi:10.1101/gad.2.3.330

References This article cites 42 articles, 24 of which can be accessed free at:

http://genesdev.cshlp.org/content/2/3/330.full.html\#ref-list-1

License

Email Alerting

Service

Receive free email alerts when new articles cite this article - sign up in the box at the top right corner of the article or click here.



